\title{
Effectiveness of a process-oriented patient-tailored outpatient neuropsychological rehabilitation programme for patients in the chronic phase after $A B I$
}

Citation for published version (APA):

Brands, I. M. H., Bouwens, S. F. M., Wolters Gregório, G., Stapert, S. Z., \& van Heugten, C. M. (2013). Effectiveness of a process-oriented patient-tailored outpatient neuropsychological rehabilitation programme for patients in the chronic phase after ABI. Neuropsychological Rehabilitation, 23(2), 202-215. https://doi.org/10.1080/09602011.2012.734039

Document status and date:

Published: 01/04/2013

DOI:

10.1080/09602011.2012.734039

Document Version:

Publisher's PDF, also known as Version of record

Document license:

Taverne

Please check the document version of this publication:

- A submitted manuscript is the version of the article upon submission and before peer-review. There can be important differences between the submitted version and the official published version of record.

People interested in the research are advised to contact the author for the final version of the publication, or visit the DOI to the publisher's website.

- The final author version and the galley proof are versions of the publication after peer review.

- The final published version features the final layout of the paper including the volume, issue and page numbers.

Link to publication

\footnotetext{
General rights rights.

- You may freely distribute the URL identifying the publication in the public portal. please follow below link for the End User Agreement:

www.umlib.nl/taverne-license

Take down policy

If you believe that this document breaches copyright please contact us at:

repository@maastrichtuniversity.nl

providing details and we will investigate your claim.
}

Copyright and moral rights for the publications made accessible in the public portal are retained by the authors and/or other copyright owners and it is a condition of accessing publications that users recognise and abide by the legal requirements associated with these

- Users may download and print one copy of any publication from the public portal for the purpose of private study or research.

- You may not further distribute the material or use it for any profit-making activity or commercial gain

If the publication is distributed under the terms of Article $25 \mathrm{fa}$ of the Dutch Copyright Act, indicated by the "Taverne" license above, 


\section{Neuropsychological Rehabilitation}

\section{Effectiveness of a process-oriented patient- tailored outpatient neuropsychological rehabilitation programme for patients in the chronic phase after $A B I$}

I. M. H. Brands , S. F. M. Bouwens , G. Wolters Gregório , S. Z. Stapert \& C. M. van Heugten

To cite this article: I. M. H. Brands , S. F. M. Bouwens , G. Wolters Gregório , S. Z. Stapert \& C. M. van Heugten (2013) Effectiveness of a process-oriented patient-tailored outpatient neuropsychological rehabilitation programme for patients in the chronic phase after $A B I$, Neuropsychological Rehabilitation, 23:2, 202-215, DOI: 10.1080/09602011.2012.734039

To link to this article: https://doi.org/10.1080/09602011.2012.734039

\section{Published online: 30 Oct 2012.}

Submit your article to this journal $[\pi$

Џlll Article views: 572

Q View related articles ¿

Citing articles: 5 View citing articles $\square$ 


\title{
Effectiveness of a process-oriented patient-tailored outpatient neuropsychological rehabilitation programme for patients in the chronic phase after $\mathrm{ABI}$
}

\author{
I. M. H. Brands ${ }^{1 *}$, S. F. M. Bouwens ${ }^{2,3 *}$, G. Wolters \\ Gregório $^{2}$, S. Z. Stapert ${ }^{4}$, and C. M. van Heugten ${ }^{2,4}$ \\ ${ }^{1}$ Blixembosch Rehabilitation Centre, Department of Neurorehabilitation, \\ Eindhoven, The Netherlands \\ ${ }^{2}$ School for Mental Health and Neuroscience, Faculty of Health, Medicine \\ and Life Sciences, Maastricht University, Maastricht, The Netherlands \\ ${ }^{3}$ Department of Medical Psychology, Laurentius Hospital, Roermond, The \\ Netherlands \\ ${ }^{4}$ Department of Neuropsychology and Psychopharmacology, Faculty of \\ Psychology and Neuroscience, Maastricht University, Maastricht, The \\ Netherlands
}

The objective of this prospective cohort study was to examine the effectiveness of an outpatient neuropsychological rehabilitation programme for patients with acquired brain injury (ABI) and their relatives. The participants were $26 \mathrm{ABI}$ patients with a mean age of 44.7 (SD 11.7) years and 24 caregivers. Mean time since injury was $3.0(S D$ 3.6) years. The intervention consisted of a patienttailored process-oriented neuropsychological rehabilitation programme focusing on facilitation of the adaptation process. Repeated measurements were taken prior to treatment (T0), directly after treatment (T1) and 6 months later (T2). Primary outcome measures were cognitive failures (CFQ), quality of life (SA-SIP30), and individualised goals (GAS). Patients improved significantly on individualised goals between T0 and T1 $(p<.01)$. This effect retained at T2. There were no significant differences on CFQ and SA-SIP30. The programme had a positive effect on attainment of the patient's individual goals. This was not associated with a higher level of participation or a better quality of life.

Correspondence should be addressed to I. M. H. Brands, P.O. Box 1355, 5602 BJ Eindhoven, The Netherlands. E-mail: i.brands@blixembosch.nl

*Both authors contributed equally to the manuscript. 
Keywords: Brain injury; Neuropsychological rehabilitation; Outpatient; Chronic.

\section{INTRODUCTION}

In acquired brain injury (ABI) cognitive, emotional and behavioural problems are frequently present and typically have a chronic character (Dikmen, Machamer, Powell, \& Temkin, 2003). These problems are known to interfere with many aspects of daily and social functioning (Wood \& Rutterford, 2006) and are often experienced by patients and their relatives as more disabling than the physical impairments (Hoofien, Gilboa, Vakil, \& Donovick, 2001; McCarthy et al., 2006; Pagulayan, Temkin, Machamer, \& Dikmen, 2006). In recent years, several specific cognitive rehabilitation programmes have been developed for the post-acute as well as for the chronic stage after brain injury. There is growing evidence for the effectiveness of integrated (targeting cognitive, emotional and behavioural problems) outpatient programmes in the post-acute and chronic phase after ABI (Cicerone, Mott, Azulay, \& Friel, 2004; Cicerone et al., 2008; High, Roebuck-Spencer, Sander, Struchen, \& Sherer, 2006; Ho \& Bennett, 1997; Mills, Karas, \& Alexander, 2006; Rasquin et al., 2010; Sarajuuri et al., 2005; Svendsen \& Teasdale, 2006; Tiersky et al., 2005).

Rasquin et al. (2010) recently studied the effectiveness of a low-intensity structured programme with a short, fixed duration ( 15 weeks) for patients with $\mathrm{ABI}$ in the chronic stage and their relatives. The purpose of that programme was to improve participants' insight in the consequences of ABI, to teach compensatory strategies and social skills, to exercise control over emotional reactions, and to enhance self-efficacy. They found that the programme had a positive effect on attainment of individual goals set by the patients, but this was not associated with improvements in participation level or quality of life.

Parallel to the study of Rasquin et al. (2010), we conducted a tandem study with the same research design and methodology to assess the effectiveness of a different outpatient neuropsychological rehabilitation programme for patients in the chronic phase after ABI and their relatives. The main focus of the current programme is to facilitate the emotional adjustment process after $\mathrm{ABI}$ and to support patients in finding new perspectives, goals and values in life considering the chronic cognitive and behavioural changes. Further, a distinct feature of the current programme is the application of a process-oriented and patient-tailored approach that allows for differentiation in each patient's treatment programme according to the actual stage and evolution of the adjustment and acceptance process. As a consequence, 
between-patient variation in the duration of the programme is possible. In this paper we report our study results.

\section{METHOD}

\section{Study design}

A prospective cohort study was conducted with repeated measurements before the start of the treatment programme (T0: baseline); directly after treatment (T1); and 6 months later (T2).

\section{Participants}

All patients and their relatives who had been referred to our centre (Blixembosch Rehabilitation Centre, The Netherlands) for outpatient neuropsychological rehabilitation between September 2006 and December 2007 were potential candidates for this study. This programme is developed for patients with $\mathrm{ABI}$ and their relatives, whose process of rebuilding life stagnates due to the presence of a variety of cognitive and behavioural problems. In addition, patients who experience deterioration in their functioning as a consequence of changes in environmental demands or major life events (e.g., changes in social or intimate relations, new or other job responsibilities) are candidates for this programme.

Patients were selected for participation in the programme by means of an interview with a neuropsychologist, a psychiatrist and a rehabilitation physician. Treatment focused entirely on the relatives when the patient's insight and awareness into individual problems was not sufficient for them to benefit from the treatment programme.

The following criteria were considered for participation in the effectiveness study. Patients were included if they had sustained ABI (confirmed by neurological or neuroimaging data), were aged $\geq 18$ years, and had complaints of cognitive, emotional, and/or behavioural problems that interfered with personal daily life functioning. Patients were excluded if they had progressive neurodegenerative illness (e.g., dementia, multiple sclerosis, Parkinson's disease), whiplash trauma, substance abuse and/or psychological or psychiatric disorders impeding the course of the rehabilitation process, illiteracy, or major treatment goals in the sensimotor area of functioning. Previous participation in any form of acute or sub-acute rehabilitation was not an exclusion criterion.

Relatives were included if they were the primary caregiver of the patient with $\mathrm{ABI}$ and aged over 18 years. Relatives were excluded if they had $\mathrm{ABI}$, primary psychiatric disorder, or illiteracy. 
All patients and relatives participating in the study signed an informed consent form.

\section{Intervention}

The main purpose of the programme is to promote the adjustment process in which managing the various cognitive, emotional and behavioural changes, accepting or coming to terms with these consequences and rebuilding perspective in life and finding new values and meaning in life are important issues. To achieve this, we use a process-oriented approach. This approach implies that at any moment during treatment, the components of the programme offered align with and fit closely to the actual stage and speed of adjustment and adaptation and are aimed at guiding the patient to the next step in this adjustment process. Therefore, the content, assembly and timing of the treatment modules offered are individually tailored. As a consequence, the different treatment modules do not follow a fixed protocol but are adapted to the patient's actual personal needs and goals. Consequently, between-patient variation in the duration and content of the programme is possible. The different therapy modules and the disciplines that are involved are listed in Table 1. A clinical example is described in Appendix 1.

Individual and/or group sessions are provided for patients. Relatives are involved in the patient's individual programme on a regular basis, and if necessary they participate in specific relative sessions. All group sessions are provided as open groups. All group modules are based on principles of group dynamics, processes and interventions.

Individual modules (see Table 1) for patients comprise individual cognitive rehabilitation therapy, individual occupational therapy, or other necessary sessions (e.g., individual speech therapy). Content and frequency of therapy is tailored to individual needs and goals and targets real and everyday life individual problems. The cognitive rehabilitation therapy differs with respect to individual goals, however, common elements are psycho-education, teaching compensation strategies for attention deficits and mental

TABLE 1

Different treatment modules

\begin{tabular}{ll}
\hline Module & \multicolumn{1}{c}{ Discipline } \\
\hline Individual cognitive rehabilitation therapy & Cognitive rehabilitation therapist \\
Individual occupational therapy & Occupational therapist \\
"I have changed" (patient group) & Two neuropsychologists \\
Sports and relaxation (patient group) & Two physiotherapists \\
Other therapies (when necessary) & Provided by several disciplines \\
Relatives' group (group session) & Neuropsychologist and psychiatrist \\
\hline
\end{tabular}


slowness, and training in external compensation techniques (e.g., notebooks) and internalised strategies (e.g., visual imagery) for memory problems. Individual occupational therapy focuses mainly on management of mental fatigue, guidance towards a well-balanced week structure and vocational rehabilitation.

Patient group sessions ("I have changed", see Table 1) are weekly sessions of 1.5 hours, which focus specifically on the general process of adaptation to the new and changed life with ABI. Three major themes are considered. First, recognising and facing the permanent character of the impairments, disabilities and changed self. Second, finding a way to deal with the losses. Third, re-establishing a new perspective on life. The choice of a set of new, meaningful but realistic long-term goals is an important component in rebuilding this new perspective. The format is adapted to group members with cognitive difficulties and accelerated mental fatigue. In every group session, by rotation, the focus is on one patient. His or her problems, experiences and expectations are discussed and placed in the context of the adaptation process. Progress in attainment of personal goals is evaluated. Timing of entry into these group sessions can differ: either from the very start of the treatment programme, or when stagnation is observed and further progress is expected through intensifying the approach by adding the group sessions to the treatment programme. A maximum of eight patients per group is allowed. These group sessions are offered in combination with the sports and relaxation group (60 minutes).

The relatives' group sessions focus on psycho-education, facilitating emotional adjustment and readjusting expectations. Important topics are finding out how to deal with the altered relationship (e.g., as a spouse), changed future perspectives, important values in life and exploring how to meet one's own needs in this changed context. The structure of the relatives' group is similar to that of the patient group. Relatives' group sessions are weekly sessions of one hour and 45 minutes. A maximum of eight relatives per group is allowed.

\section{Measures}

\section{Neuropsychological functioning.}

Assessment of cognitive status and cut-off scores for cognitive deficits were identical to the procedure described in the tandem study by Rasquin et al. (2010) (see Table 3). Briefly, a cognitive domain was considered impaired if one or more scores of the neuropsychological tests for that domain were below cut-off ( $S D \geq 2$ or percentile $\leq 5$ or decile $<2$ ). The purpose of neuropsychological testing was to get information about the cognitive capacities of the patient. Neuropsychological performance was no 
outcome measure as the programme focused on compensation for cognitive impairments and was not oriented towards restitution of cognitive impairments (Evans, 2006).

\section{Outcome measures.}

The outcome measures were identical to those described in the tandem study by Rasquin et al. (2010). Primary outcome measures included assessment of quality of life (Stroke-adapted Sickness Impact Profile, SA-SIP30), cognitive failures (Cognitive Failure Questionnaire, CFQ) and individualised goals (Goal Attainment Scaling, GAS). Secondary outcome measures included daily life activities (Frenchay Activities Index, FAI), physical and psychological complaints (Symptom Check List, SCL-90), community integration (Community Integration Questionnaire, CIQ), fatigue (Fatigue Severity Scale, FSS), and cognitive decline (Informant Questionnaire on Cognitive Decline, IQCODE). Outcome measures for the relatives included coping style (Utrecht Coping List, UCL) and caregiver burden (Caregiver Strain Index, CSI). All these measures were performed at T0, T1 and T2. For further detailed information we refer to the study of Rasquin et al. (2010).

\section{Statistical analysis}

Descriptive statistics were used to describe the demographic variables, neuropsychological functioning and daily functioning. A repeated measures ANOVA (general linear model with repeated measures, GLM) was conducted with the outcome scores on all primary outcome measures as within-subject variables and the time of measurement (T0, T1, T2) as between-subject variables in order to investigate the effect of treatment. Tukey post hoc tests were requested to evaluate whether differences in mean outcome scores for the different times of measurement were significant. Differences in outcome measures between patients receiving individual modules only and patients receiving both individual modules and group sessions were tested using independent samples $t$-test. Pearson's or Spearman's correlations were tested as appropriate. Statistical analyses were performed with the Statistical Package for Social Sciences (version 18.0) with an alpha level set at .05 for all analyses.

\section{RESULTS}

\section{Participants}

During the study period, 31 patients were treated. Five patients refused participation in the study, the remaining 26 patients were included (Table 2). 
TABLE 2

Patient characteristics

\begin{tabular}{lcc}
\hline & Patients $(\mathrm{n}=26)$ & Relatives $(\mathrm{n}=23)$ \\
\hline Men $n(\%)$ & $19(73)$ & $6(26)$ \\
Age at assessment (years) mean $(S D)$ range & $44.6(11.7) 23-67$ & $50.1(10.4) 27-68$ \\
Time since injury (years) mean $(S D)$ range & $3.0(3.6) 0.4-13$ & \\
Therapy duration (months) mean $(S D)$ range & $8.8(4.7) 2-19.5$ & \\
Amount of therapy (hours) mean $(S D)$ range & $66.7(68.0), 4.5-202.1$ & \\
Education, low-medium-high $n(\%)$ & $6(23)-11(42)-9(35)$ & \\
Cause of injury $n(\%)$ & & \\
Stroke & $9(35)$ & \\
TBI & $10(38)$ & \\
SAH & $4(15)$ & \\
Brain tumour & $1(4)$ & \\
Viral infection & $1(4)$ & \\
HBI & $1(4)$ & \\
\hline
\end{tabular}

TBI: traumatic brain injury; SAH: subarachnoid haemorrhage; HBI: hypoxic brain injury.

Twelve patients completed a treatment programme that was exclusively composed of individual modules, and the remaining 14 patients completed a treatment programme consisting of both individual modules and group sessions. Total therapy duration in months was not different between these two subgroups of patients $(7.6 \pm 4.2$ versus $9.9 \pm 5.1$ months, respectively, $p=$ .23 ), whereas therapy duration in hours was significantly greater in those who followed both individual modules and group sessions $(19.3 \pm 11.4$ versus $107.3 \pm 70.2$ hours, respectively, $p<.001$ ).

Neuropsychological functioning is presented in Table 3. Deficits were found in all cognitive domains except abstract reasoning. Most deficits were found in the field of executive functioning, followed by attention and memory.

\section{Short-term effects of the programme}

Table 4 presents the results of the primary and secondary outcome measures. GAS scores increased between T0 and T1 $(p<.01)$, indicating a significant degree of attainment of predefined individual goals. None of the other outcome measures was significantly different between T0 and T1. Notably, the decrease in SCL-90 scores between T0 and T1 reached borderline significance $(p=.05)$.

GAS scores at T1 were not different between patients who followed individual modules only versus those who followed both individual modules and group sessions $(54.8 \pm 13.9$ versus $51.5 \pm 10.7$, respectively, $p=.49$ ). No significant correlations were observed between GAS scores at $\mathrm{T} 1$ and 
TABLE 3

Neuropsychological functioning, including number of patients with a deficit

\begin{tabular}{lccc}
\hline & Mean (SD) & Range & N deficit \\
\hline Short-term memory & & & \\
WAIS III Digit Span & $14.3(3.2)$ & $10.0-21.0$ & \\
Episodic memory & & & 6 \\
AVLT & $41.4(10.6)$ & $4.5-60.0$ & 8 \\
RCFT (delayed recall) & $18.0(7.3)$ & & \\
Attention & & $65.0-480.0$ & 7 \\
d2 & $284.4(125.3)$ & $16.0-162.0$ & \\
TMT A & $48.7(34.2)$ & $36.0-0.0$ & 7 \\
Executive functioning & $105.8(74.2)$ & $62.0-405.0$ & \\
TMT B & $120.0(67.0)$ & & 4 \\
Stroop & & $2.0-5.0$ & 5 \\
BADS & $4.8(0.6)$ & $0.0-16.0$ & 2 \\
Action Plan & $11.6(4.5)$ & $0.0-9.0$ & \\
Zoo Map & $1.4(2.5)$ & $1.0-6.0$ & 0 \\
Rule Shift & $5.2(1.3)$ & $110.0-120.0$ & 4 \\
Six Elements & $115.8(2.9)$ & $12.0-53.0$ & 4 \\
Language & $30.0(11.6)$ & $8.0-46.0$ & 0 \\
AAT & $19.4(5.1)$ & & \\
Phonetic fluency & $19.0(7.7)$ & & \\
Semantic fluency & Abstract reasoning & & \\
WAIS III Matrices & & & \\
\hline
\end{tabular}

WAIS III: Wechsler Adult Intelligence Test; AVLT: Auditory Verbal Learning Test; RCFT: Rey Complex Figure Test; d2: the d2 test of attention; TMT: Trail Making Test, part A and B; BADS: Behavioural Assessment of the Dysexecutive Syndrome; AAT: Aachen Aphasia Test.

therapy duration in months $(r=.14, p=.51)$ or amount of therapy in hours $(\rho=.07, p=.75)$.

\section{Long-term effects of the programme}

None of the outcome measures changed significantly between T1 and T2 (all $p \mathrm{~s}$ $\geq .05$, Table 4). At T2, GAS scores were still significantly higher than at $\mathrm{T} 0$, and were not different from T1, indicating a long-term stability in the degree of attainment of predefined individual goals (Figure 1). A trend was observed towards lower CSI scores at T2 compared to T0 $(p=.07)$ and to T1 $(p=.05)$.

\section{Content of individualised goals}

Table 5 gives an overview of the distribution of the number of goals set in the general and specific domains. In total 93 goals were set. The mean $(S D)$ number of goals was 3.6 (1.1) per participant (range 2-6). Most goals were 
TABLE 4

Mean scores on the questionnaires, differences between the assessments

\begin{tabular}{|c|c|c|c|c|c|c|}
\hline Questionnaire & TOMean (SD) & T1 Mean (SD) & T2 Mean (SD) & T0-T1 $p$-value $(N)$ & T1-T2 p-value (N) & $T 0-T 2 \mathrm{p}$-value (N) \\
\hline \multicolumn{7}{|l|}{ Patient } \\
\hline SA-SIP Total & $22.6(12.8)$ & $23.0(13.8)$ & $22.5(15.1)$ & $1.00(19)$ & $1.00(19)$ & $1.00(19)$ \\
\hline SA-SIP Physical & $9.1(10.5)$ & $11.5(12.4)$ & $10.0(13.2)$ & $1.00(19)$ & $1.00(19)$ & $1.00(19)$ \\
\hline SA-SIP Psychosocial & $34.4(17.7)$ & $34.0(20.8)$ & $33.3(22.7)$ & $1.00(19)$ & $1.00(19)$ & $1.00(19)$ \\
\hline CFQ & $44.9(17.6)$ & $41.7(16.3)$ & $42.3(14.6)$ & $.67(20)$ & $1.00(20)$ & $.80(20)$ \\
\hline GAS & $32.5(3.8)$ & $52.9(12.4)$ & $55.5(11.9)$ & $<.01(25)^{*}$ & $.50(25)$ & $<.01(25)^{*}$ \\
\hline FAI & $25.1(6.8)$ & $27.7(7.1)$ & $28.1(7.8)$ & $.22(20)$ & $1.00(20)$ & $.09(20)$ \\
\hline SCL-90 & $154.8(48.8)$ & $136.3(32.3)$ & $141.4(36.0)$ & $.05(20)$ & $1.00(20)$ & $.43(20)$ \\
\hline CIQ & $17.9(5.3)$ & $17.9(4.9)$ & $18.3(5.1)$ & $1.00(19)$ & $1.00(19)$ & $1.00(19)$ \\
\hline FSS & $2.9(1.5)$ & $3.0(1.6)$ & $3.0(1.2)$ & $1.00(20)$ & $1.00(20)$ & $1.00(20)$ \\
\hline IQCODE & $3.4(0.7)$ & $3.5(0.6)$ & $3.2(0.7)$ & $.22(24)$ & $.92(21)$ & $.17(23)$ \\
\hline UCL Active reaction & $17.1(3.4)$ & $17.0(3.5)$ & $18.1(4.0)$ & $1.00(19)$ & $.54(19)$ & $.78(19)$ \\
\hline UCL Palliative reaction & $16.7(4.0)$ & $16.9(3.0)$ & $17.2(4.9)$ & $1.00(19)$ & $1.00(19)$ & $1.00(19)$ \\
\hline UCL Avoidance & $17.2(4.3)$ & $16.8(4.3)$ & $16.4(4.3)$ & $1.00(19)$ & $1.00(19)$ & $.82(19)$ \\
\hline UCL Seeking social support & $12.6(3.3)$ & $13.1(2.7)$ & $13.7(4.2)$ & $1.00(19)$ & $.93(19)$ & $.19(19)$ \\
\hline UCL Passive reaction pattern & $12.6(3.9)$ & $12.0(3.3)$ & $11.7(4.0)$ & $.86(19)$ & $1.00(19)$ & $.79(19)$ \\
\hline UCL Expression of emotions & $5.9(1.6)$ & $6.1(1.7)$ & $5.7(1.8)$ & $1.00(19)$ & $1.00(19)$ & $1.00(19)$ \\
\hline UCL Reassuring thoughts & $10.9(2.4)$ & $11.1(2.1)$ & $11.7(2.7)$ & $1.00(19)$ & $.79(19)$ & $.39(19)$ \\
\hline \multicolumn{7}{|l|}{ Relative } \\
\hline UCL Active reaction & $18.1(3.2)$ & $17.4(5.0)$ & $16.6(4.8)$ & $1.00(17)$ & $.62(17)$ & $.13(17)$ \\
\hline UCL Palliative reaction & $16.5(3.0)$ & $15.5(3.9)$ & $16.6(3.4)$ & $.67(17)$ & $.58(17)$ & $1.00(17)$ \\
\hline UCL Avoidance & $14.9(2.5)$ & $16.1(3.2)$ & $14.8(2.3)$ & $.35(17)$ & $.08(17)$ & $1.00(17)$ \\
\hline UCL Seeking social support & $12.8(3.1)$ & $11.4(2.7)$ & $11.6(3.4)$ & $.12(17)$ & $1.00(17)$ & $.65(17)$ \\
\hline UCL Passive reaction pattern & $10.5(2.5)$ & $9.8(2.0)$ & $10.0(2.5)$ & $.40(17)$ & $1.00(17)$ & $.86(17)$ \\
\hline UCL Expression of emotions & $5.5(1.4)$ & $5.5(1.2)$ & $5.7(1.4)$ & $1.00(17)$ & $1.00(17)$ & $1.00(17)$ \\
\hline UCL Reassuring thoughts & $11.9(2.3)$ & $11.4(2.6)$ & $10.9(2.4)$ & $.92(17)$ & $.53(17)$ & $.27(17)$ \\
\hline CSI & $5.5(2.8)$ & $5.1(2.7)$ & $3.7(2.3)$ & $1.00(15)$ & $.05(15)$ & $.07(15)$ \\
\hline
\end{tabular}

${ }^{*}: p<.05$; SA-SIP: Stroke Adapted Sickness Impact Profile; CFQ: Cognitive Failure Questionnaire; GAS: Goal Attainment Scaling; FAI: Frenchay Activities Index; SCL-90: Symptom Checklist; CIQ: Community Integration Questionnaire; FSS: Fatigue Severity Scale; IQCODE: Informant Questionnaire on Cognitive Decline; UCL: Utrecht Coping List; CSI: Caregiver Strain Index.

T0-T1: Effect from before to directly after programme.

T1-T2: Effect from directly after programme to 6 months later. 
TABLE 5

Domains of goals

\begin{tabular}{|c|c|c|c|c|c|c|c|}
\hline Cognition & $N$ & Emotion & $\mathrm{N}$ & Behaviour & $\mathrm{N}$ & Other & $\mathrm{N}$ \\
\hline Memory & 10 & Self-esteem & 1 & $\begin{array}{l}\text { Impulsivity/ } \\
\text { inhibition }\end{array}$ & 1 & Work-related & 3 \\
\hline $\begin{array}{l}\text { Attention/ } \\
\text { concentration }\end{array}$ & 5 & Acceptance & 9 & $\begin{array}{l}\text { Aggression/ } \\
\text { temper }\end{array}$ & 6 & Education & 2 \\
\hline $\begin{array}{l}\text { Planning/ } \\
\text { organising }\end{array}$ & 6 & Mood & 2 & Assertiveness & 4 & Peer support & 1 \\
\hline Structure & 4 & Burden & 5 & Social skills & 1 & Administration & 5 \\
\hline Strategy use & 8 & $\begin{array}{l}\text { Coping with } \\
\text { emotions }\end{array}$ & 1 & Fatigue & 6 & & \\
\hline Flexibility & 1 & Enjoy life again & 2 & Take some rest & 3 & & \\
\hline Preoccupation & 1 & & & Affective feelings & 3 & & \\
\hline Making choices & 1 & & & Talkative & 1 & & \\
\hline Time pressure & 1 & & & & & & \\
\hline Total & 37 & & 20 & & 25 & & 11 \\
\hline
\end{tabular}

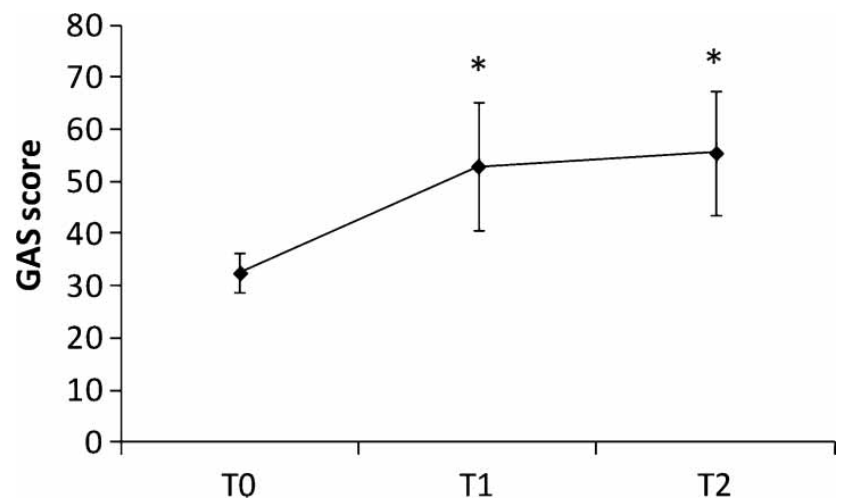

Figure 1. Overall Goal Attainment Scaling $(\mathrm{GAS})$ score. $\mathrm{T} 0=$ prior to treatment; $\mathrm{T} 1=$ immediately after termination of treatment; $\mathrm{T} 2=6$ months after termination of treatment. ${ }^{*} p<.01$ compared with $\mathrm{T} 0$.

set in the cognitive domain (e.g., memory and strategy use), followed by the behavioural domain (e.g., fatigue and aggression).

\section{DISCUSSION}

We showed that this process-oriented patient-tailored outpatient neuropsychological rehabilitation programme for patients in the chronic phase after ABI had a positive effect on the attainment of the patients' pre-defined 
goals, and this effect was maintained six months after termination of the programme. We did not find a change in any of the other primary outcome measures reflecting quality of life and cognitive failures. Moreover, none of the secondary outcome measures either for patients or relatives showed any significant change.

The results of this study are strikingly similar to those of the tandem study by Rasquin et al. (2010), despite the substantial differences in content and structure between the treatment programmes. The programme presented here is patienttailored and process-oriented, not fixed, and has a longer duration. It consists of individual and/or open group sessions and the main focus is to rebuild a new perspective on life. Family and relative involvement is promoted. The programme described by Rasquin et al. (2010) is a highly protocolled programme consisting of closed group sessions. The main focus is oriented towards management of and compensation for the cognitive impairments.

The positive effects on GAS in both studies might be explained in part by shared characteristics of both programmes, such as information provision, group sessions enabling the contact with and support from fellow-patients, and positive reinforcement.

The lack of effect on quality of life and general participation level might be due to the lower intensity level of this programme compared to other programmes (Geurtsen, Martina, Van Heugten, \& Geurts, 2008; Sarajuuri et al., 2005; Tiersky et al., 2005).

Quality of life scores showed no change in response to the current programme. Perhaps, as therapists, we overestimate the contribution of treatment effects on quality of life, especially in lower intensity programmes. Moreover, since the main purpose of the programme is to promote the adaptation process, key clinical treatment results are shifts in expectations, the ability to create a new perspective on life, and the process of choosing new but realistic long-term goals (Brands, Wade, Stapert, \& Van Heugten, 2012). This shift in reference point is essential but is probably not captured in the generic outcome measures used.

Furthermore, the results of both studies suggest that these more generic outcome measures do not focus sufficiently on the patient's personal problems and perspective. When applying the International Classification of Functioning (ICF) framework (World Health Organization, 2001) to the current treatment programme, it is clearly noticeable that by choosing an individually tailored process-oriented approach, particular attention is paid to the involvement and influence of "personal" factors. Although relatives are involved ("environmental" factor), the personal focus stands out. In this perspective, it is not surprising that goal attainment scaling, which is completely patient-centred (Bouwens, van Heugten, \& Verhey, 2009) shows obvious effects.

Would other outcome measures have been more suitable for detecting treatment effects of the current programme? Perceived self-efficacy has been 
defined as one's belief in one's ability to accomplish activities and achieve outcomes consistent with one's expectations (Bandura, 1989). As Cicerone already noted, perceived self-efficacy may play a fundamental role in one's ability to reduce the (real or potential) discrepancy between achievements and expectations. An increased level of self-efficacy may reflect an increased sense of mastery and acceptance of one's limitations (Cicerone \& Azulay, 2007). As such, measurement of self-efficacy fits tighter to the general purpose of our programme, which is promotion of compensation and adjustment. At the time we designed this study, the brain-injury specific measure of self-efficacy developed by Cicerone and Azulay was not available.

Therapy duration and amount of therapy differed largely between individual patients. This was expected considering that the design of the programme allowed for inter-individual differences. Nevertheless, this may complicate the interpretation of the data. The largest amount of therapy was seen in the group of patients attending the combination of group and individual therapy, whereas therapy duration was not significantly different from the group of patients attending an exclusively individual programme. From a clinical perspective these findings are not surprising because the patients who show greater difficulties in their emotional adjustment process and management of their impairments are allocated to the group sessions, which allows for a more intensive approach (see Method section). The group of patients who, based on clinical judgement, need a less intensive approach to meet treatment goals are offered an exclusively individual programme. So, retrospectively reflecting on our clinical practice, two levels of treatment intensity are revealed. This may explain why neither therapy duration nor amount of therapy in hours was associated with accomplishment of individually set pre-defined goals (GAS scores) at T1.

The current study was performed to examine the effectiveness of a newly developed neuropsychological rehabilitation programme, and provides a first indication of its effects on a wide array of outcome measures. With the prepost intervention design employed in the current study, we lacked a control group, which complicates the interpretation of our data. Therefore, a randomised controlled trial is indicated in order to assess whether the observed effect on GAS is induced by the intervention.

In conclusion, this neuropsychological rehabilitation programme showed a positive and long-lasting effect on attainment of individualised goals but none of the more generic outcome measures showed a positive effect of the treatment.

\section{REFERENCES}

Bandura, A. (1989). Regulation of cognitive processes through perceived self-efficacy. Developmental Psychology, 25, 729-735. 
Bouwens, S. F., van Heugten, C. M., \& Verhey, F. R. (2009). The practical use of goal attainment scaling for people with acquired brain injury who receive cognitive rehabilitation. Clinical Rehabilitation, 23, 310-320.

Brands, I., Wade, D., Stapert, S., \& Van Heugten, C. (2012). The adaptation process following acute onset disability: An interactive two-dimensional approach applied to acquired brain injury. Clinical Rehabilitation, 26, 840-852.

Cicerone, K. D., \& Azulay, J. (2007). Perceived self-efficacy and life satisfaction after traumatic brain injury. Journal of Head Trauma Rehabilitation, 22, 257-266.

Cicerone, K. D., Mott, T., Azulay, J., \& Friel, J. C. (2004). Community integration and satisfaction with functioning after intensive cognitive rehabilitation for traumatic brain injury. Archives of Physical Medicine and Rehabilitation, 85, 943-950.

Cicerone, K. D., Mott, T., Azulay, J., Sharlow-Galella, M. A., Ellmo, W. J., Paradise, S., \& Friel, J. C. (2008). A randomized controlled trial of holistic neuropsychologic rehabilitation after traumatic brain injury. Archives of Physical Medicine and Rehabilitation, 89, 2239-2249.

Dikmen, S. S., Machamer, J. E., Powell, J. M., \& Temkin, N. R. (2003). Outcome 3 to 5 years after moderate to severe traumatic brain injury. Archives of Physical Medicine and Rehabilitation, 84, 1449-1457.

Evans, J. (2006). Memory rehabilitation-should we be aiming for restoration or compensation? Journal of Neurology, 253, 520-521.

Geurtsen, G. J., Martina, J. D., Van Heugten, C. M., \& Geurts, A. C. H. (2008). A prospective study to evaluate a new residential community reintegration programme for severe chronic brain injury: The Brain Integration Programme. Brain Injury, 22, 545-554.

High, J. W. M., Roebuck-Spencer, T., Sander, A. M., Struchen, M. A., \& Sherer, M. (2006). Early versus later admission to postacute rehabilitation: Impact on functional outcome after traumatic brain injury. Archives of Physical Medicine and Rehabilitation, 87, 334-342.

Ho, M. R., \& Bennett, T. L. (1997). Efficacy of neuropsychological rehabilitation for mildmoderate traumatic brain injury. Archives of Clinical Neuropsychology, 12, 1-11.

Hoofien, D., Gilboa, A., Vakil, E., \& Donovick, P. J. (2001). Traumatic brain injury (TBI) 1020 years later: A comprehensive outcome study of psychiatric symptomatology, cognitive abilities and psychosocial functioning. Brain Injury, 15, 189-209.

McCarthy, M. L., Dikmen, S. S., Langlois, J. A., Selassie, A. W., Gu, J. K., \& Horner, M. D. (2006). Self-reported psychosocial health among adults with traumatic brain injury. Archives of Physical Medicine and Rehabilitation, 87, 953-961.

Mills, V. M., Karas, A., \& Alexander, M. P. (2006). Outpatient rehabilitation of patients with chronic cognitive impairments after ruptured anterior communicating artery aneurysms reduces the burden of care: A pilot study. Brain Injury, 20, 1183-1188.

Pagulayan, K. F., Temkin, N. R., Machamer, J., \& Dikmen, S. S. (2006). A longitudinal study of health-related quality of life after traumatic brain injury. Archives of Physical Medicine and Rehabilitation, 87, 611-618.

Rasquin, S. M. C., Bouwens, S. F. M., Dijcks, B., Winkens, I., Bakx, W. G. M., \& van Heugten, C. M. (2010). Effectiveness of a low intensity outpatient cognitive rehabilitation programme for patients in the chronic phase after acquired brain injury. Neuropsychological Rehabilitation, 20, 760-777.

Sarajuuri, J. M., Kaipio, M.-L., Koskinen, S. K., Niemelä, M. R., Servo, A. R., \& Vilkki, J. S. (2005). Outcome of a comprehensive neurorehabilitation program for patients with traumatic brain injury. Archives of Physical Medicine and Rehabilitation, 86, 2296-2302.

Svendsen, H. A., \& Teasdale, T. W. (2006). The influence of neuropsychological rehabilitation on symptomatology and quality of life following brain injury: A controlled long-term follow-up. Brain Injury, 20, 1295-1306. 
Tiersky, L. A., Anselmi, V., Johnston, M. V., Kurtyka, J., Roosen, E., Schwartz, T., \& DeLuca, J. (2005). A trial of neuropsychologic rehabilitation in mild-spectrum traumatic brain injury. Archives of Physical Medicine and Rehabilitation, 86, 1565-1574.

Wood, R. L., \& Rutterford, N. A. (2006). Demographic and cognitive predictors of long-term psychosocial outcome following traumatic brain injury. Journal of the International Neuropsychological Society, 12, 350-358.

World Health Organization (2001). International classification of functioning, disability and health, Available from http://www3.who.int/icf/icftemplate.cfm.

Manuscript received February 2012

Revised manuscript September 2012

First published online October 2012

\section{APPENDIX 1}

\section{Clinical example}

In order to make better adjustments to the experienced problems in daily life it may be obvious that the consistent use of certain compensatory strategies are necessary for Mr Brown, a middle-aged man with a traumatic brain injury that occurred 14 months ago. However, Mr Brown considers his problems as being of a temporary nature and expects full recovery. He rejects the use of compensation techniques and prefers an impairment-oriented treatment approach resulting in a drill and practice attitude towards his cognitive problems.

In this example, the primordial subject matter of intervention will be the patient's long-term perspective and expectations about future functioning. Therefore, Mr Brown's treatment programme consists of weekly group sessions to share experiences with peers and to receive feedback. Teaching strategies and compensatory methods will follow when the patient has altered his perspective, is more aware of the permanent character of the impairments, and is convinced of the necessity and benefits of strategy use. At that point, individual cognitive therapy and occupational therapy will be added to his programme. The vanishing of hopes for natural recovery may lead to mourning reactions, depressed mood, and anxiety responses. Group sessions will be continued to monitor these responses and create a new and altered perspective on life. 